
\title{
Resesarch Sulure \\ The Relationship between Sleep Hygiene, Mood, and Insomnia Symptoms in Men with Prostate Cancer
}

\author{
Kathleen T. Galvin
}

University of Otago

Sheila N. Garland

Memorial University of Newfoundland

Erik Wibowo ( $\square$ erik.wibowo@otago.ac.nz )

University of Otago https://orcid.org/0000-0002-5309-1490

\section{Research Article}

Keywords: prostate cancer, sleep, anxiety, sleep hygiene, depression, treatment side effects, fatigue, sleepiness

Posted Date: July 27th, 2021

DOI: https://doi.org/10.21203/rs.3.rs-665325/v1

License: (c) (1) This work is licensed under a Creative Commons Attribution 4.0 International License. Read Full License

Version of Record: A version of this preprint was published at Supportive Care in Cancer on January 22nd, 2022. See the published version at https://doi.org/10.1007/s00520-021-06680-1. 


\section{Abstract}

\section{Purpose}

Insomnia symptoms are commonly experienced by men after prostate cancer (PCa) treatment. Here we explored how sleep hygiene behaviours and psychological symptoms are associated with insomnia symptoms in PCa patients.

\section{Methods}

An online survey was posted on social media and sent to mailing lists of PCa and general cancer organisations. The survey collected information on demographic, sleep hygiene and psychological symptoms using validated questionnaires.

\section{Results}

Data from 142 participants were compared based on the absence (age $=68.3 \pm 8.9$ years) and presence (age $=66.6 \pm 9.0$ years) of insomnia symptoms. Participants with insomnia symptoms had significantly higher levels of anxiety, depression, fatigue, and daytime sleepiness as well as poorer sleep hygiene than those without insomnia symptoms. Control variables (age, comorbidities, ADT experience and BMI) accounted for $12.5 \%$ of the variance in insomnia symptoms. Adding sleepiness, fatigue, anxiety, depressive symptoms to the model explained an additional $45.1 \%$ of the variance in insomnia symptoms. Further, including the sleep hygiene item "I think, plan, or worry when I am in bed" and "I sleep in an uncomfortable bedroom" explained an additional $3.6 \%$ of the variance in insomnia symptoms.

\section{Conclusions}

Poor sleep hygiene, fatigue, daytime sleepiness, anxiety, depressive symptoms were all associated with worse insomnia symptoms in PCa patients. Improving sleep hygiene and treating psychological conditions may potentially help prevent and/or alleviate insomnia symptoms in PCa patients.

\section{Introduction}

Men with prostate cancer ( $\mathrm{PCa}$ ) are two to three time more likely to experience insomnia symptoms than men without prostate cancer $[6,10,14,32,34]$. A recent study also showed that poor sleep is associated with higher odds for having high-grade PCa [44]. Insomnia symptoms are also related to other symptoms in PCa patients, including depression, fatigue, and daytime sleepiness $[6,17,36]$. Considering that insomnia is associated with poorer psychological outcomes in cancer patients $[5,17]$, it is important to further our understanding of what factors influence insomnia severity in PCa patients in order to improve their quality of life.

Insomnia symptoms among PCa patients can be a result of cancer treatment [32] and tend to be long lasting [30]. Prostatectomy and external beam radiation are often prescribed for localised PCa, but both 
may lead to urinary symptoms that can ultimately cause a disruption to sleep. A previous study reported that $31.5 \%$ of prostatectomy patients experienced insomnia symptoms [34]. In a sample of men who received brachytherapy, radical prostatectomy, or radiation, $32 \%$ reported insomnia symptoms, with men who received radiation reporting more severe insomnia [16]. Severe urinary symptoms have been shown to mediate the relationship between insomnia symptoms and receiving radiation therapy alone [32]. Another common treatment for PCa is androgen deprivation therapy [9] which can be prescribed for systemic PCa or as an adjuvant therapy to radiation therapy [39]. ADT is associated with significantly worse insomnia symptoms [14,33] which have been attributed to the hot flashes, night sweats, and nocturia that result from deprivation of their gonadal androgens [41, 43]. Accordingly, hot flashes, night sweats and nocturia, have also been demonstrated to mediate the relationship between ADT and insomnia symptoms $[14,32]$. Combined, it is clear that these treatments, while intended to treat disease and prevent recurrence, also come with the potential to negatively impact sleep, which can place these men at risk for poorer physical and mental recovery.

Several other factors may also be associated with insomnia symptoms in PCa patients, such as younger age, insomnia symptoms before treatment, depression, and anxiety $[7,23,26]$. Sleep habits may also influence sleep quality. For example, sleep hygiene, the practice of performing behaviours that may facilitate or hinder sleep, has been studied in a wide variety of populations that may experience sleeping difficulties. Poor sleep hygiene, such as using the bed for activities other than sleep and sex as well as alcohol and caffeine consumption, are associated with worse sleep in non-cancer patients [2,37], but the relationship between sleep hygiene practices and insomnia symptoms in PCa patients has not been well investigated. Recent research shows that patients are generally quite willing to improve their sleep hygiene [6]. While sleep hygiene improvement alone is not sufficient to alleviate insomnia symptoms [8, 38], sleep hygiene education is often included as a component of cognitive behaviour therapy (CBT) for insomnia [12]. It is important to understand which sleep hygiene behaviours influence the experience of insomnia symptoms in men with PCa as part of a more comprehensive treatment plan.

Here, we aim to further understand how sleep hygiene behaviours are associated with insomnia symptoms in PCa patients. Secondly, we will explore how psychological parameters are associated with insomnia symptoms, because some sleep hygiene behaviours appear to be related to psychological symptoms. For example, some behaviours like thinking and worrying while in bed, or going to bed whilst feeling distressed may be due to depression or anxiety. Others may relate to fatigue or sleepiness, such as taking prolonged or frequent daytime naps. These psychological variables have been studied previously in PCa patients [42], and may have a bidirectional relationship with insomnia symptoms (as shown in the general population) [18].

\section{Methods}

\section{Participants}


We recruited men with PCa who accessed an online survey through a link posted by PCa support groups and organisations on their social media. The survey was approved by the University of Otago Human Ethics Committee (Health) (H18/078) and built using the Research Electronic Data Capture (REDCap).

The survey link generated from REDCap was then distributed to support groups and organisations who were contacted via email. This survey took approximately 45 minutes to complete. Once the person had consented to the study, they could then access the questionnaires.

The survey was active from August 2018 to May 2019. Within this period, those surveys which were only partially completed were excluded from the analysis. In this study, 442 people accessed the survey link, and 218 consented to the study. From this, 76 were removed because of missing data. The final number of participants for the analyses in this paper was 142.

\section{Measures}

\section{Demographic}

Demographic information including age, ethnicity, location, income, education, relationships status, job, comorbidities, and PCa treatment history was collected by self-report.

\section{Insomnia Severity Index}

Insomnia symptoms were assessed using the Insomnia Severity Index (ISI) [1]. This questionnaire asks about difficulty falling asleep, staying asleep, problems with waking too early, and satisfaction with current sleep pattern. In addition, the ISI also includes questions on how worried one is about their current sleep quality, how noticeable they think it is to others, and how much their potential sleep problems interfere with their daily functioning. Each item was rated on a scale from 0-4, with a higher score indicating more severe insomnia symptoms. The cut-off scores for no, mild, moderate and severe insomnia symptoms were $0-7,8-14,15-21$, and 22-28 respectively. The internal consistency in our sample was $\mathrm{a}=0.90$.

\section{Sleep hygiene}

The Sleep Hygiene Index [24] was used to measure how frequently the participant engaged in 13 behaviours that can potentially affect their quality of sleep. For example, it asks about frequency of getting out of bed and into bed at different times each day, or using alcohol, tobacco or caffeine within 4 hours of going to bed. Each item was rated on a 5-point scale; with a higher score indicating worse sleep hygiene. The answer options range from 'always' to 'never'. The internal consistency in our sample was a $=0.74$.

\section{Anxiety}

Anxiety levels were measured by the Generalised Anxiety Disorder (GAD-7) screening questionnaire [22]. This measure asks about the frequency of seven behaviours related to anxiety; covering worry, irritability 
and trouble relaxing during the last two weeks. Each item was measured on a scale 0-3 with a higher total score indicating more severe anxious symptoms. The internal consistency in our sample was a $=0.92$.

\section{Depression}

Depressive symptoms were measured using the Center for Epidemiologic Studies Depression (CES-D) Scale [29]. This questionnaire assessed the frequency of 20 depressive symptoms like being bothered and loss of appetite within the last week. Each question was measured on a scale of 0-3 with a higher total score indicating more severe depressive symptoms. The internal consistency in our sample was a = 0.89 .

\section{Fatigue}

Fatigue levels were measured using the Brief Fatigue Inventory (BFI) [25]. This scale assessed the level of fatigue as well as how fatigue had interfered with participant's functioning across a variety of parameters within the past 24 hours. This included the level of fatigue at that moment, generally in the last 24 hours and the worst level experienced in the previous 24 hours. Each item was measured on a scale of 0-10, with a higher score indicating a higher level of interference. The internal consistency in our sample was $\mathrm{a}=0.96$.

\section{Daytime sleepiness}

Daytime sleepiness was measured by the Epworth Sleepiness Scale (ESS) [19]. This questionnaire measured the likelihood of the patient falling asleep in different daytime situations (e.g. when reading, talking to someone or sitting after lunch). Each item was measured on a scale from 0-3, with a higher score indicating a higher chance of dozing. The internal consistency in our sample was a $=0.79$.

\section{Data analyses}

These data were analysed using SPSS statistics software (IBM version 25). Demographic data were summarized based on the presence $(\geq 8)$ or absence $(<8)$ of insomnia symptoms, using descriptive statistics. A distribution of ISI scores of our participants was also presented. We compared the sleep hygiene score as well as fatigue, daytime sleepiness, depressive and anxiety symptoms of our participants based on whether they experienced insomnia symptoms, using a between subjects t-test. In addition, we performed hierarchical multiple regression analyses on our sample to determine whether sleep hygiene behaviours were associated with insomnia symptoms. For this analysis, we controlled for variables which are associated with increased risk of insomnia symptoms: ADT treatment history [14], age [27], BMI [3] and number of comorbidities [31]. In step 1, control variables were entered. In Step 2, the total sleepiness (ESS), anxiety (GAD-7), depressive symptoms score (CES-D), and fatigue (BFI) were added. In step 3, various sleep hygiene behaviours were step-wise entered into the model. $p<0.05$ was considered significant. 


\section{Results}

\section{Demographic}

Table 1 summarises the demographic characteristics of participants in our study, based on their ISI score. Participants without insomnia symptoms $(\mathrm{N}=56,39.4 \%)$ were $68.3 \pm 8.9$ years old on average, with $87.5 \%$ of participants being in a relationship for $34.6 \pm 15.3$ years. Of the partners, $98 \%$ were female and had an average age of $66.0 \pm 8.3$ years. $85.7 \%$ of these participants identified as Caucasian, $92.9 \%$ were either retired or had full-time employment. $75 \%$ had a university education and $68 \%$ had a household income of at least $\$ 50,000$. The most common comorbidities were depression, heart attack and circulation problems $(12.5 \%, 9.1 \%$ and $8.9 \%$ respectively). In regards to their treatment history, participants had most commonly received prostatectomy (68.8\%), radiation therapy $(55.0 \%)$ and androgen deprivation therapy (44.7\%). 
Table 1

Sociodemographic characteristics of participants, based on their ISI scores.

Insomnia Symptoms

Variables

Age

Ethnicity

Caucasian

Non-Caucasian

In a relationship $70(83.3)$

\section{Relationship}

status

Living with partner/spouse

Not living together

Relationship

duration (years)

Partner's age

Partner's gender

Female

Male

$N(\%)$

$M(S D)$

$66.6(9.0)$

No Insomnia Symptoms

$N(\%) \quad M(S D)$

$68.3(8.9)$
69 (84.1)

$13(15.9)$

69 (98.6)

1 (1.4)

$35.5(14.3)$

$63.2(9.8)$
$48(85.7)$

8 (14.3)

49

(87.5)

\begin{tabular}{|lll|}
\hline Female & $67(97.1)$ & $48(98.0)$ \\
\hline Male & $2(2.9)$ & $1(2.0)$ \\
\hline Marital status & & $2(3.6)$ \\
\hline Never married & $2(2.4)$ & $48(85.7)$ \\
\hline Married/civil union & $67(79.8)$ & $0(0.0)$ \\
\hline Common law & $3(3.6)$ & $0(0.0)$ \\
\hline Separated & $3(3.6)$ & $6(10.7)$ \\
\hline Divorced & $6(7.2)$ & $0(0.0)$ \\
\hline Widowed & $3(3.6)$ & $17(30.4)$ \\
\hline Employment & $25(30.5)$ & $4(7.1)$ \\
\hline Full time & $9(11.0)$ & $0(0.0)$ \\
\hline Part time & $2(2.4)$ & \\
\hline Looking for a job & & \\
\hline
\end{tabular}


Retired

\section{Education}

Primary school or less

Some secondary school or polytechnic
Secondary school or polytechnic graduate

Some university

Undergraduate/bachelors

Graduate or professional degree
$46(56.1)$

$35(62.5)$

\begin{tabular}{|lll|}
\hline \begin{tabular}{|l|l|} 
Secondary school or polytechnic \\
graduate
\end{tabular} & $16(19.0)$ & $11(19.6)$ \\
\hline Some university & $18(21.4)$ & $5(8.9)$ \\
\hline Undergraduate/bachelors & $24(28.6)$ & $14(25.0)$ \\
\hline Graduate or professional degree & $20(23.8)$ & $23(41.1)$ \\
\hline $\begin{array}{l}\text { Combined } \\
\text { household income }\end{array}$ & $2(2.4)$ & $1(1.9)$ \\
\hline Less than $\$ 10,000$ & $6(7.3)$ & $5(9.4)$ \\
\hline$\$ 10,000-\$ 30,000$ & $9(11)$ & $11(20.8)$ \\
\hline$\$ 30,001-\$ 50,000$ & $34(41.5)$ & $11(20.8)$ \\
\hline$\$ 50,000-\$ 100,000$ & $31(37.8)$ & $25(47.2)$ \\
\hline More than $\$ 100,000$ & & \\
\hline
\end{tabular}

Participants with insomnia symptoms ( $N=84,59.2 \%)$ were an average of $66.6 \pm 9.0$ years old, with $83.3 \%$ in a relationship for $35.5 \pm 14.3$ years. $97.1 \%$ of their partners were female, with an average age $63.2 \pm 9.8$ years. $84.1 \%$ identified as Caucasian, $86.6 \%$ either had full-time employment or were retired. $73.8 \%$ had at least some university education and $79.3 \%$ had a combined household income of at least $\$ 50,000$. The most common comorbidities (depression, heart attack and circulation problems) had prevalence rates of $13.6 \%, 13.9 \%$ and $12.8 \%$ respectively for those with insomnia symptoms. The most common treatments were prostatectomy $(68 \%)$, radiation therapy $(46.5 \%)$ and androgen deprivation therapy $(44.6 \%)$.

\section{Insomnia symptoms in PCa patients}

As shown on Fig. 1, 40\%, 38.5\%, 18.5\%, and $2.8 \%$ of our participants had no, mild, moderate and severe insomnia symptoms respectively. Levels of anxiety $(t(133=-4.716, p<.001)$, depression $(t(124)=-5.868$, $p<.001)$, fatigue $(t(138)=-6.146, p<.001)$ and daytime sleepiness $(t(133)=-2.980, p=.003)$ are all significantly higher in participants with insomnia symptoms compared to those without symptoms of insomnia (Fig. 2). 
As shown on Table 2, participants with insomnia symptoms scored significantly higher for two sleep hygiene behaviours that those without symptoms of insomnia; these are "I go to bed feeling stressed, angry, upset or nervous" $(t(136)=-5.912, p<.001)$ and "I think, plan or worry when I am in bed" $(t(138)=$ $-4.397, p<.001)$. In addition, Table 3 shows how sleep hygiene behaviours are associated with insomnia in our sample. The control variables (age, ADT experience, comorbidities, BMI) accounted for $12.5 \%$ of the variance in insomnia symptoms. When scores for anxiety, depression, fatigue and sleepiness were added, an additional $45.1 \%$ of the variance was accounted for. When the sleep hygiene items were added in stepwise method, only two items contributed to additional $3.6 \%$ of the variance in insomnia symptoms. These were "I think, plan, or worry when I am in bed" $(\beta=.188, p=.032)$ and "I sleep in an uncomfortable bedroom" $(\beta=-.138, p=.041)$.

Table 2

Sleep hygiene parameters compared between those with and without insomnia symptoms. Data is presented as mean (standard deviation). ***Significantly different between groups, $p<.001$.

\section{Sleep Hygiene parameters}

Insomnia Symptoms

'I take daytime naps lasting two or more hours'

'I go to bed at different times from day to day'

'I get out of bed at different times from day to day'

'I exercise to the point of sweating within 1 hour of going to bed'

'I stay in bed longer than I should two or three times a week'

'I use alcohol tobacco or caffeine within 4 hr of going to bed or after going to bed'

'I do something that may wake me up before bedtime (eg; play videogames, use the internet or clean)'

\section{'I go to bed feeling stressed, angry, upset or nervous'***}

'I use my bed for things other than sleeping or sex'

'I sleep on an uncomfortable bed'

'I sleep in an uncomfortable bedroom'

'I do important work before bedtime'

'I think, plan or worry when I am in bed'***

$\begin{array}{ll}.88 \pm .96 & .67 \pm .76 \\ 1.5 \pm .92 & 1.3 \pm .83 \\ 1.6 \pm .95 & 1.4 \pm .74\end{array}$

$.27 \pm .59 \quad .18 \pm .47$

$.72 \pm .83$

$.67 \pm .92$

$1.4 \pm 1.2$

$1.3 \pm 1.2$

$1.3 \pm 1.1$

$1.2 \pm 1.1$

$1.3 \pm .77$

$.66 \pm .67$

$1.5 \pm 1.4$

$1.2 \pm 1.2$

$.45 \pm .78$

$.35 \pm .67$

$.36 \pm .68$

$.50 \pm .72$

$.82 \pm .93$

$.90 \pm .90$

$2.1 \pm 1.0$

$1.4 \pm .96$ 
Table 3

Hierarchical regression on how sleep hygiene behaviours predict insomnia symptoms.

\begin{tabular}{|c|c|c|c|c|c|}
\hline & B & SE B & $\boldsymbol{\beta}$ & $R^{2}$ & $p$ value \\
\hline \multicolumn{6}{|l|}{ Sleep hygiene } \\
\hline Step 1 & & & & .125 & .009 \\
\hline Constant & 25.481 & 7.011 & & & $<.001$ \\
\hline Age & -.199 & .068 & -.284 & & .004 \\
\hline Number of comorbidities & 1.382 & .568 & .233 & & .017 \\
\hline BMI & -.186 & .150 & -.126 & & .217 \\
\hline ADT experience & .932 & 1.195 & .074 & & .437 \\
\hline Step 2 & & & & .576 & $<.001$ \\
\hline Constant & 10.372 & 5.321 & & & .054 \\
\hline Age & -.044 & .053 & -.063 & & .404 \\
\hline Number of comorbidities & -.233 & .434 & -.039 & & .593 \\
\hline BMI & -.196 & .109 & -.132 & & .075 \\
\hline ADT experience & .358 & .871 & .028 & & .682 \\
\hline Sleepiness & .309 & .114 & .204 & & .008 \\
\hline Anxiety & .456 & .135 & .354 & & .001 \\
\hline Depression & .092 & .078 & .143 & & .243 \\
\hline Fatigue & .732 & .256 & .283 & & .005 \\
\hline Step 3 & & & & .595 & .036 \\
\hline Constant & 8.016 & 5.343 & & & .137 \\
\hline Age & -.044 & .052 & -.063 & & .394 \\
\hline Number of comorbidities & -.074 & .433 & -.013 & & .864 \\
\hline BMI & -.141 & .110 & -.095 & & .205 \\
\hline ADT experience & .202 & .859 & .016 & & .814 \\
\hline Sleepiness & .277 & .113 & .183 & & .016 \\
\hline
\end{tabular}

In the first block, age, body mass index (BMI), number of comorbidities, ADT experience $(1=$ No, $2=$ Yes) were entered. For the second block, the total score for sleepiness (ESS), anxiety (GAD-7), depressive symptoms (CES-D), Fatigue (BFI) were entered. In the third block, items from the Sleep Hygiene Index were step-wise entered into the model. $p s<.05$ are indicated in bold. 


\begin{tabular}{|c|c|c|c|c|c|}
\hline & B & SE B & $\beta$ & $R^{2}$ & $p$ value \\
\hline Anxiety & .347 & .142 & .270 & & .017 \\
\hline Depression & .049 & .080 & .076 & & .543 \\
\hline Fatigue & .836 & .256 & .323 & & .002 \\
\hline "I think, plan, or worry when I am in bed" & 1.022 & .481 & .186 & & .036 \\
\hline Step 4 & & & & .612 & .041 \\
\hline Constant & 8.779 & 5.267 & & & .099 \\
\hline Age & -.046 & .051 & -.066 & & .367 \\
\hline Number of comorbidities & -.142 & .427 & -.024 & & .740 \\
\hline BMI & -.136 & .108 & -.092 & & .212 \\
\hline ADT experience & -.097 & .857 & -.008 & & .910 \\
\hline Sleepiness & .262 & .111 & .173 & & .021 \\
\hline Anxiety & .365 & .140 & .284 & & .011 \\
\hline Depression & .055 & .078 & .086 & & .481 \\
\hline Fatigue & .889 & .254 & .343 & & .001 \\
\hline "I think, plan, or worry when I am in bed" & 1.030 & .473 & .188 & & .032 \\
\hline "I sleep in an uncomfortable bedroom" & -1.10 & .535 & -.138 & & .041 \\
\hline \multicolumn{6}{|c|}{$\begin{array}{l}\text { In the first block, age, body mass index (BMI), number of comorbidities, ADT experience }(1=\text { No, } 2= \\
\text { Yes) were entered. For the second block, the total score for sleepiness (ESS), anxiety (GAD-7), } \\
\text { depressive symptoms (CES-D), Fatigue (BFI) were entered. In the third block, items from the Sleep } \\
\text { Hygiene Index were step-wise entered into the model. } p s<.05 \text { are indicated in bold. }\end{array}$} \\
\hline
\end{tabular}

\section{Discussion}

Insomnia is common among PCa patients due to either psychological distress or treatment side effects. In this study we show that insomnia symptoms are associated with various psychological (anxiety, depression, fatigue, sleepiness) as well as lifestyle (sleep hygiene) factors in the PCa population. These findings stress that PCa patients also experience concurrent psychological symptoms in addition to insomnia symptoms. Treating insomnia symptoms in this patient population may potentially alleviate other psychological symptoms. While insomnia requires a multi-modal treatment to manage it, our finding also suggest the importance of including sleep hygiene education for insomnia management in PCa patient population. 
In our study, $60 \%$ of participants had at least mild insomnia symptoms ( $\geq 8 \mathrm{ISI}$ score). This is consistent with Gonzalez et al. [14] who reported that $59 \%$ of PCa patients had $\geq 8$ ISI score at one year after receiving ADT. Further, our findings are in line with Maguire et al [23] who reported that $19 \%$ of patients endorsed "quite a bit" or "very much" trouble sleeping during the last week, which is similar to the $21.3 \%$ of our sample which reported moderate or severe sleep problems. Other published research has reported lower estimates of insomnia symptom prevalence. Savard et al. [34] found that $29.4 \% \%$ of men who received prostatectomy had $\geq 8 \mathrm{ISI}$ score. Similarly, Savard et al. [32] also showed that $41.9 \%$ of patients who received ADT as an adjuvant therapy to radiation therapy reported $\geq 8$ ISI score. Differences in treatments received might explain these differences, with receipt of ADT being associated with higher insomnia severity. Regardless, the presence of insomnia suggests that this symptom should be assessed for and appropriately managed.

Patients who had more severe insomnia symptoms reported significantly higher presence anxiety and depressive symptoms. While there is some evidence in the general population to support a causal relationship between insomnia and mood disturbance [15, 21], it is likely that there are also other confounding factors at play. For example, a wide range of PCa treatment side effects can also affect sleep such as hot flashes and urinary symptoms [14]. Furthermore, these side effects may also augment psychological symptoms that are present. These data therefore stress the importance of assessing and treating a variety of factors that may be of a detriment to a patients sleep. Cognitive Behavioral Therapy for Insomnia (CBT-I) remains the first line intervention in cancer patients $[12,20]$ and the general population [28].

One component of CBT-I is sleep hygiene education. Our data supports the notion that behavioural adjustment may potentially help patients sleep better such as by avoiding going to bed while being distressed [4]. However, sleep hygiene improvement alone may not be sufficient as patients may have additional problems they face that affect their sleep (e.g., treatment side effects). For example, many PCa patients experience depression and anxiety [42], both of which are associated with insomnia symptoms in our sample. Thus, clinicians may need to manage these symptoms too.

\section{Coi}

ncidentally, some sleep hygiene behaviours that were associated with insomnia symptoms appear to be related to anxiety-related behaviours, e.g., worrying or being distressed in bed. There are two possible explanations for this; that insomnia symptoms are causing more stress and worry around bedtime, or that stress and worry around bedtime is causing insomnia symptoms $[35,40]$. In the general population, there is a bi-directional relationship between anxiety and insomnia [18]. Such a relationship may also be present in the PCa population. Healthcare providers may need to work with patients to identify their source of anxiety and psychological distress, and plan how to best work together with patients in addressing these problems so they can have less anxiety or distress while in bed.

We also found that insomnia symptoms are related to sleepiness and fatigue. This is likely because insufficient sleep may be leaving the patient fatigued and having excessive daytime sleepiness. This 
finding is consistent with data from a previous study [6], where both daytime sleepiness and fatigue were elevated in participants with severe insomnia symptoms. Our data also suggest that treating insomnia symptoms in these patients is important to reduce fatigue and daytime sleepiness. Such a treatment may potentially improve patients' daytime functioning and work productivity.

\section{Limitations}

The limitations of this study include the fact that the majority of the patients were Caucasian, with a university education and high household income. Therefore, this data may not be fully representative of the wider PCa population. Furthermore, the data were collected online, so they may not reflect those patients who are not internet-users. In addition, the self-report nature of the data may influence the accuracy, as we cannot confirm the survey data with clinical data. However, we attempt to minimise this by using validated questionnaires and by seeking help from cancer organisations to post our questionnaires. In addition, $60 \%$ of our participants have at least mild insomnia symptoms, suggesting that our survey may have been biased towards patients with insomnia even though the study was not advertised to recruit for men experiencing this symptom. Our team is currently conducting a follow-up study using actigraphy and hormonal measurements to confirm data presented in this paper. These follow up data will give objective confirmation on sleep-wake parameters and the actual hormonal profiles of the patients.

\section{Clinical Implications}

Our study has important clinical implications to the survivorship of PCa patients as many experience insomnia symptoms after receiving treatment. As stated above, treating insomnia symptoms in this patient population is likely to involve multiple approaches. CBT-I remains the treatment recommended for improving insomnia in cancer patients $[12,20]$. Furthermore, our data support the importance of integrating sleep hygiene education in CBT for PCa patients. Mindfulness therapy could be another potential treatment for insomnia in PCa patients as psychological factors appear to be common predictors for insomnia $[11,13]$. We are not aware of any studies that have investigated either therapy solely in PCa patients. However, their efficacies have been proven in breast cancer patients [45], and warrants exploration in PCa patient population.

\section{Conclusion}

In conclusion, our findings support the fact that poor sleep hygiene and psychological symptoms are associated with insomnia symptoms in PCa patients. These data emphasise the complexity of insomnia symptoms in PCa patients, and suggest that their treatment will likely require multiple approaches. In addition, the sleep hygiene education component of CBT-I is likely to be important for ensuring that patients are engaging in behaviours that facilitate their sleep. Future studies could explore interventions such as CBT-I or mindfulness for alleviating insomnia symptoms in PCa patients. PCa patients generally endorse both strategies, and those with high insomnia symptoms are more likely to use CBT-I than those with low insomnia symptoms [6]. 


\section{Declarations}

Funding: This research is funded by a start-up funding to Dr Erik Wibowo from the Department of Anatomy at the University of Otago.

Conflicts of interest/Competing interests: None

Availability of data and material (data transparency): Data are not archived in a repository.

Code Availability: N/A

Authors' contributions: Conceptualization: EW, SG; Methodology: EW, SG, KG; Formal analysis and investigation: EW, SG, KG; Writing - original draft preparation: KG; Writing - review and editing: EW, SG, KG; Funding acquisition: EW; Resources: EW; Supervision: EW

Ethics approval: The survey was approved by the University of Otago Human Ethics Committee (Health) (H18/078).

Consent to participate (include appropriate statements): All participants consented to the study prior to completing the survey.

\section{Consent for Publication: N/A}

Acknowledgement: We thank various PCa support groups and organisations who helped distribute our survey including: Prostate Cancer Foundation New Zealand, Prostate Cancer International, Cancer Society NZ, Prostate Cancer Foundation BC, Canadian Cancer Society, Prostate Problems Mailing List, Cancer Survivors Network, Prostate Cancer Foundation, Cancer Society Ireland, Prostate Cancer Foundation Australia, Prostate Cancer Centre Calgary, SurvivorNet.

\section{References}

1. Bastien $\mathrm{CH}$, Vallieres A, Morin CM (2001) Validation of the Insomnia Severity Index as an outcome measure for insomnia research. Sleep Med 2(4):297-307. https://doi.org/10.1016/S1389-9457(00)000654

2. Brick CA, Seely DL, Palermo TM (2010) Association between sleep hygiene and sleep quality in medical students. Behav Sleep Med 8(2):113-121. https://doi.org/10.1080/15402001003622925

3. Chan WS, Levsen MP, McCrae CS (2018) A meta-analysis of associations between obesity and insomnia diagnosis and symptoms. Sleep Med Rev 40170-182. https://doi.org/10.1016/j.smrv.2017.12.004

4. Chung KF, Lee CT, Yeung WF, Chan MS, Chung EW, Lin WL (2018) Sleep hygiene education as a treatment of insomnia: a systematic review and meta-analysis. Fam Pract 35(4):365-375. 
https://doi.org/10.1093/fampra/cmx122

5. Davis MP, Goforth HW (2014) Long-term and short-term effects of insomnia in cancer and effective interventions. Cancer J 20(5):330-344. https://doi.org/10.1097/PP0.0000000000000071

6. Delpachitra S, Campbell A, Wibowo E (2020) Preference for sleep management strategies among prostate cancer patients: an Aotearoa/New Zealand perspective. Cancer Treat Res Commun 25(2020):100219. https://doi.org/10.1016/j.ctarc.2020.100219

7. Dirksen SR, Epstein DR, Hoyt MA (2009) Insomnia, depression, and distress among outpatients with prostate cancer. Appl Nurs Res 22(3):154-158. https://doi.org/10.1016/j.apnr.2007.09.001

8. Edinger JD, Arnedt JT, Bertisch SM, Carney CE, Harrington JJ, Lichstein KL, Sateia MJ, Troxel WM, Zhou ES, Kazmi U, Heald JL, Martin JL (2020) Behavioral and psychological treatments for chronic insomnia disorder in adults: an American Academy of Sleep Medicine clinical practice guideline. J Clin Sleep Med https://doi.org/10.5664/jcsm.8986

9. Elliott S, Latini DM, Walker LM, Wassersug R, Robinson JW (2010) Androgen deprivation therapy for prostate cancer: recommendations to improve patient and partner quality of life. J Sex Med 7(9):29963010. https://doi.org/10.1111/j.1743-6109.2010.01902.x

10. Galvin KT, Garland SN, Wibowo E (2020) The association between insomnia and orgasmic difficulty for prostate cancer patients - implication to sex therapy. J Sex Marital Ther 47(2):174-185. https://doi.org/10.1080/0092623X.2020.1848947

11. Garland SN, Carlson LE, Stephens AJ, Antle MC, Samuels C, Campbell TS (2014) Mindfulnessbased stress reduction compared with cognitive behavioral therapy for the treatment of insomnia comorbid with cancer: a randomized, partially blinded, noninferiority trial. J Clin Oncol 32(5):449-457. https://doi.org/10.1200/JC0.2012.47.7265

12. Garland SN, Johnson JA, Savard J, Gehrman P, Perlis M, Carlson L, Campbell T (2014) 3. Neuropsychiatr Dis Treat 10:1113-1124. https://doi.org/10.2147/NDT.S47790

13. Garland SN, Zhou ES, Gonzalez BD, Rodriguez N (2016) The quest for mindful sleep: a critical synthesis of the impact of mindfulness-based interventions for insomnia. Curr Sleep Med Rep 2(3):142151. https://doi.org/10.1007/s40675-016-0050-3

14. Gonzalez BD, Small BJ, Cases MG, Williams NL, Fishman MN, Jacobsen PB, Jim HSL (2018) Sleep disturbance in men receiving androgen deprivation therapy for prostate cancer: The role of hot flashes and nocturia. Cancer 124(3):499-506. https://doi.org/10.1002/cncr.31024

15. Hertenstein E, Feige B, Gmeiner T, Kienzler C, Spiegelhalder K, Johann A, Jansson-Frojmark M, Palagini L, Rucker G, Riemann D, Baglioni C (2019) Insomnia as a predictor of mental disorders: a 
systematic review and meta-analysis. Sleep Med Rev 43:96-105.

https://doi.org/10.1016/j.smrv.2018.10.006

16. Hervouet S, Savard J, Simard S, Ivers H, Laverdiere J, Vigneault E, Fradet Y, Lacombe L (2005) Psychological functioning associated with prostate cancer: cross-sectional comparison of patients treated with radiotherapy, brachytherapy, or surgery. J Pain Symptom Manage 30(5):474-484. https://doi.org/10.1016/j.jpainsymman.2005.05.011

17. Irwin MR (2013) Depression and insomnia in cancer: prevalence, risk factors, and effects on cancer outcomes. Curr Psychiatry Rep 15(11):404. https://doi.org/10.1007/s11920-013-0404-1

18. Jansson-Frojmark M, Lindblom K (2008) A bidirectional relationship between anxiety and depression, and insomnia? A prospective study in the general population. J Psychosom Research 64(4):443-449. https://doi.org/10.1016/j.jpsychores.2007.10.016

19. Johns MW (1991) A new method for measuring daytime sleepiness: the Epworth sleepiness scale. Sleep 14(6):540-545. https://doi.org/10.1093/sleep/14.6.540

20. Johnson JA, Rash JA, Campbell TS, Savard J, Gehrman PR, Perlis M, Carlson LE, Garland SN (2016) A systematic review and meta-analysis of randomized controlled trials of cognitive behavior therapy for insomnia (CBT-I) in cancer survivors. Sleep Med Rev 27:20-28. https://doi.org/10.1016/j.smrv.2015.07.001

21. Li L, Wu C, Gan Y, Qu X, Lu Z (2016) Insomnia and the risk of depression: a meta-analysis of prospective cohort studies. BMC psychiatry 16(1):375. https://doi.org/10.1186/s12888-016-1075-3

22. Lowe B, Decker O, Muller S, Brahler E, Schellberg D, Herzog W, Herzberg PY (2008) Validation and standardization of the Generalized Anxiety Disorder Screener (GAD-7) in the general population. Med Care 46(3):266-274. https://doi.org/10.1097/MLR.0b013e318160d093

23. Maguire R, Drummond FJ, Hanly P, Gavin A, Sharp L (2019) Problems sleeping with prostate cancer: exploring possible risk factors for sleep disturbance in a population-based sample of survivors. Support Care Cancer 27(9):3365-3373. https://doi.org/10.1007/s00520-018-4633-z

24. Mastin DF, Bryson J, Corwyn R (2006) Assessment of sleep hygiene using the Sleep Hygiene Index. J Behav Med 29(3):223-227. https://doi.org/10.1007/s10865-006-9047-6

25. Mendoza TR, Wang XS, Cleeland CS, Morrissey M, Johnson BA, Wendt JK, Huber SL (1999) The rapid assessment of fatigue severity in cancer patients: use of the Brief Fatigue Inventory. Cancer 85(5):1186-1196. https://doi.org/10.1002/(SICI)1097-0142(19990301)85:5<1186::AID-CNCR24>3.0.C0;2$\mathrm{N}$

26. Miaskowski C, Paul SM, Cooper BA, Lee K, Dodd M, West C, Aouizerat B, Dunn L, Swift PS, Wara W (2011) Predictors of the trajectories of self-reported sleep disturbance in men with prostate cancer during 
and following radiation therapy. Sleep 34(2):171-179. https://doi.org/10.1093/sleep/34.2.171

27. Mong JA, Cusmano DM (2016) Sex differences in sleep: impact of biological sex and sex steroids. Philos Trans R Soc Lond B Biol Sci 371(1688):20150110. https://doi.org/10.1098/rstb.2015.0110

28. Qaseem A, Kansagara D, Forciea MA, Cooke M, Denberg TD, Clinical Guidelines Committee of the American College of P (2016) Management of chronic insomnia disorder in adults: a clinical practice guideline from the American College of Physicians. Ann Intern Med 165(2):125-133. https://doi.org/10.7326/M15-2175

29. Radloff LS (1977) The CES-D Scale: a self-report depression scale for research in the general population. Appl Psychol Meas 1(3):385-401. https://doi.org/10.1177/014662167700100306

30. Reynolds-Cowie P, Fleming L (2020) Living with persistent insomnia after cancer: a qualitative analysis of impact and management. Br J Health Psychol 26(1):33-49.

https://doi.org/10.1111/bjhp.12446

31. Sarsour K, Morin CM, Foley K, Kalsekar A, Walsh JK (2010) Association of insomnia severity and comorbid medical and psychiatric disorders in a health plan-based sample: insomnia severity and comorbidities. Sleep Med 11(1):69-74. https://doi.org/10.1016/j.sleep.2009.02.008

32. Savard J, Hervouet S, Ivers H (2013) Prostate cancer treatments and their side effects are associated with increased insomnia. Psychooncology 22(6):1381-1388.

https://doi.org/10.1002/pon.3150

33. Savard J, Ivers H, Savard MH, Morin CM (2015) Cancer treatments and their side effects are associated with aggravation of insomnia: results of a longitudinal study. Cancer 121(10):1703-1711. https://doi.org/10.1002/cncr.29244

34. Savard J, Simard S, Hervouet S, Ivers H, Lacombe L, Fradet Y (2005) Insomnia in men treated with radical prostatectomy for prostate cancer. Psychooncology 14(2):147-156. https://doi.org/10.1002/pon.830

35. Sella E, Borella E (2020) Strategies for controlling sleep-related intrusive thoughts, and subjective and objective sleep quality: how self-reported poor and good sleepers differ. Aging Ment Health https://doi.org/10.1080/13607863.2020.1783513

36. Sharp L, O'Leary E, Kinnear H, Gavin A, Drummond FJ (2015) Cancer-related symptoms predict psychological wellbeing among prostate cancer survivors: results from the PiCTure study. Psychooncology 25(3):282-291. https://doi.org/10.1002/pon.3909

37. Shriane AE, Ferguson SA, Jay SM, Vincent GE (2020) Sleep hygiene in shift workers: a systematic literature review. Sleep Med Rev 53101336. https://doi.org/10.1016/j.smrv.2020.101336 
38. Sidani S, Epstein DR, Fox M, Collins L (2019) Comparing the effects of single-and multiplecomponent therapies for insomnia on sleep outcomes. Worldviews Evid Based Nurs 16(3):195-203. https://doi.org/10.1111/wvn.12367

39. Smith MR (2007) Androgen deprivation therapy for prostate cancer: new concepts and concerns. Curr Opin Endocrinol Diabetes Obes 14(3):247-254. https://doi.org/10.1097/MED.0b013e32814db88c

40. Tutek J, Gunn HE, Lichstein KL (2021) Worry and rumination have distinct associations with nighttime versus daytime sleep symptomology. Behav Sleep Med 19(2):192-207. https://doi.org/10.1080/15402002.2020.1725012

41. Wassersug RJ, Walker LM, Robinson JW (2018) Androgen deprivation therapy: an essential guide for prostate cancer patients and their loved ones. With contributions from: Currie KL, Kukula K, LawlorSavage L, Matthew A, McLeod D, Santa Mina D, Van Patten C, Wibowo E. Demos Health, New York

42. Watts S, Leydon G, Birch B, Prescott P, Lai L, Eardley S, Lewith G (2014) Depression and anxiety in prostate cancer: a systematic review and meta-analysis of prevalence rates. BMJ Open 4(3):e003901. https://doi.org/10.1136/bmjopen-2013-003901

43. Wibowo E, Wassersug RJ, Robinson JW, Matthew A, McLeod D, Walker L (2019) How are patients with prostate cancer managing androgen deprivation therapy side effects? Clin Genitourin Cancer 17(3):e408-e419. https://doi.org/10.1016/j.clgc.2018.12.006

44. Wiggins EK, Oyekunle T, Howard LE, Markt SC, Mucci LA, Bliwise DL, Moreira DM, Andriole GL, Hopp ML, Freedland SJ, Allott EH (2020) Sleep quality and prostate cancer aggressiveness: results from the REDUCE trial. Prostate 80(15):1304-1313. https://doi.org/10.1002/pros.24052

45. Zeichner SB, Zeichner RL, Gogineni K, Shatil S, loachimescu O (2017) Cognitive behavioral therapy for insomnia, mindfulness, and yoga in patients with breast cancer with sleep disturbance: a literature review. Breast Cancer (Auckl) 111178223417745564. https://doi.org/10.1177/1178223417745564

\section{Figures}




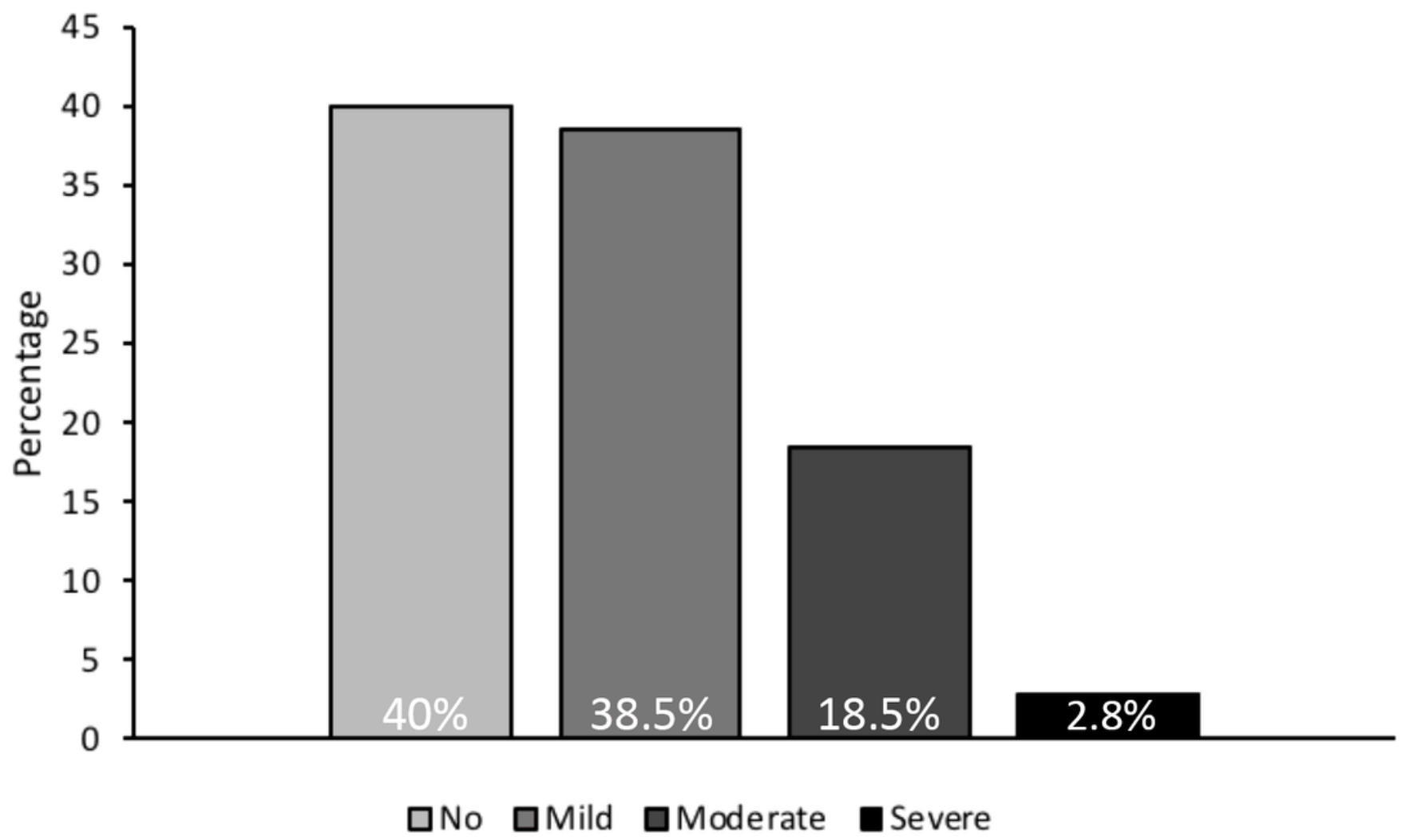

Figure 1

Percentages of participants with no, mild, moderate, and severe insomnia symptoms in our study sample. 
A

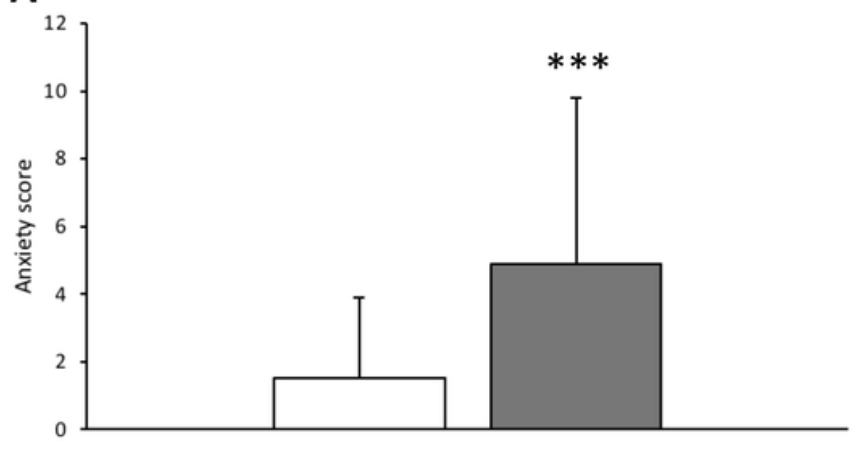

C

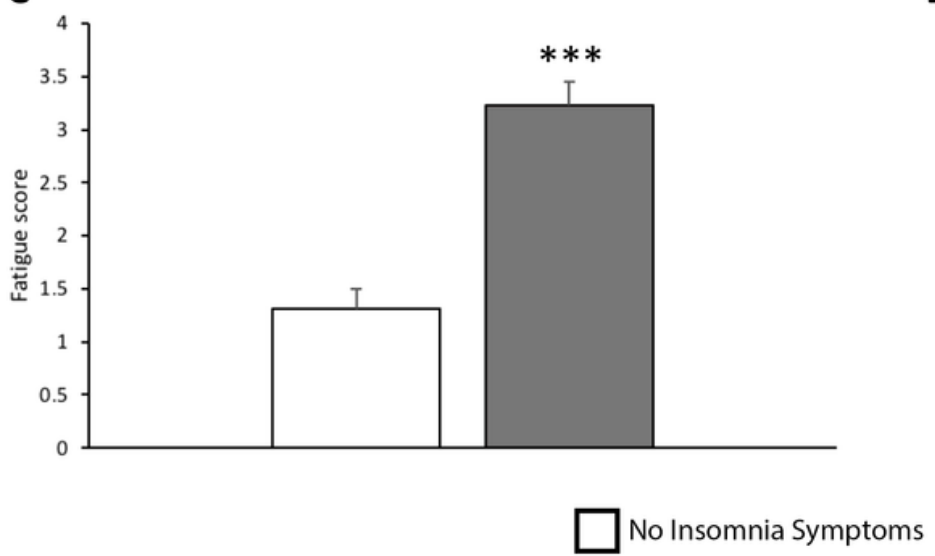

B

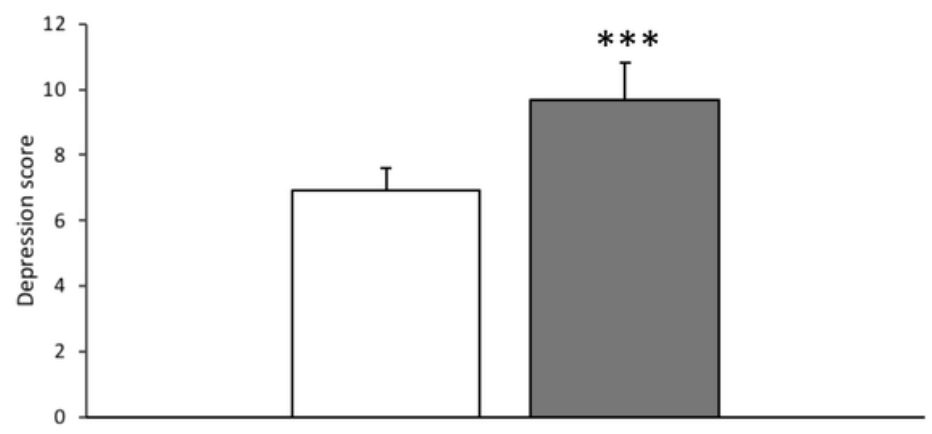

D

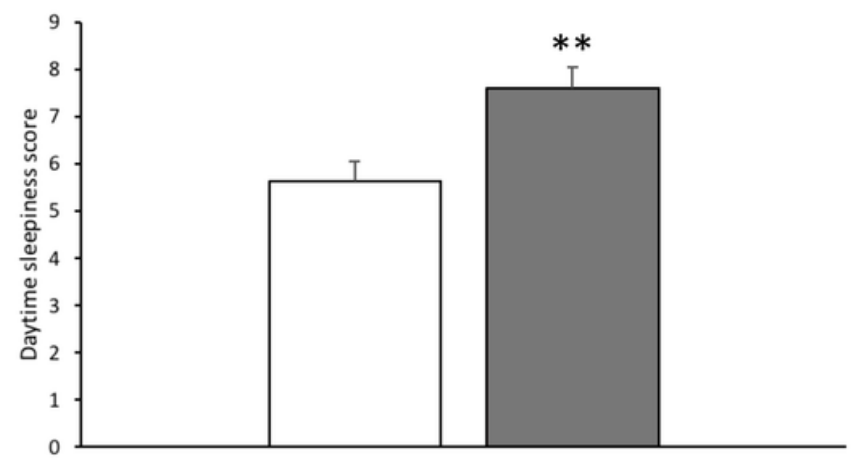

Insomnia Symptoms

\section{Figure 2}

Anxiety symptoms (A), depressive symptoms (B), fatigue (C) and daytime sleepiness (D) scores of participants with or without insomnia symptoms. Those with insomnia symptoms scores had significantly higher score for the anxiety symptoms, depressive symptoms than participants without

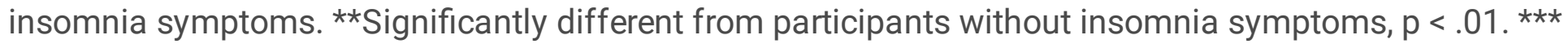
$p<.001$ 